\title{
Code-switching Analysis in TCFL Classroom from the Perspective of Sociolinguistics
}

\author{
Juan Ma \\ Foreign Languages School, Shanxi Normal University, Linfen, China
}

\begin{abstract}
With the increasingly frequent international exchanges and cooperation, bilingualism and multilingualism have become a common social phenomenon. Along with this social trend, sociolinguistics, was once regarded as a marginal and small branch of linguistic research, which has been paid a growing number of attention from linguists and scholars in this field in recent years. Code switching is a central topic in sociolinguistics. In the past few decades, a large number of scholars have done a lot of research about code switching from articles, journals and books. Although many achievements have been made in code conversion in recent years, little work has been done in teaching Chinese as a foreign language. With the rapid development and immaturity of teaching Chinese as a foreign language, it is only in a marginal position in teaching methods and foreign language teaching research system. Based on linguistic theory, this paper analyzes the causes and functions of code switching in foreign Chinese teachers' classroom teaching by observing the phenomenon of code switching in foreign Chinese teachers' classroom teaching and conducting follow-up interviews with teachers and students after class. The results show that teachers can help students to accept new knowledge more effectively and they highlight the key points and difficulties in class, so teachers play an important role in improving the teaching quality. In addition, the conclusion reflects the actual situation of teaching Chinese as a foreign language to a certain extent, and provides a reference for improving the teaching ability and classroom teaching effect of foreign Chinese teachers.
\end{abstract}

Index Terms - code, code conversion, teaching Chinese as a foreign language, sociolinguistics

\section{INTRODUCTION}

This part mainly introduces the background, objectives, significance, questions, and structure of the research.

\section{A. Research Background}

Code conversion defined by Myers-Scotton (1993) is the use of two or more languages in the same conversation, usually in the same conversation, or even in the same sentence at the turn. So far, a lot of research has been done by scholars and it has happened in different fields. As a research field, it has rich and diverse literature, including research based on various theoretical models and research methods. Transcendence is also known as code mixing and is defined by Liebscher (2005) as "systematic use of two languages or language variants in a single conversation or discourse". It is common in many bilingual environments, such as the SL / setup FL classroom. And classroom code conversion is a very complex language phenomenon, it is not only similar to code conversion in bilingual society, but also unique in model. Further research is needed to go beyond TCSL (using Chinese as a second language) to play an important role in TCSL. Based on the study of code switching in second language acquisition, this paper aims to explore the current situation of code switching in TCSL classroom and analyze its causes. Furthermore, both teachers and students use code switching provide valuable advice for the research in the future.

\section{B. Objectives and Significance of the Research}

In fact, code conversion takes place between teachers and students start at the same time, which show different characteristics and functions as a consequence. So it is completely necessary to observe and study these two situations in real time to reflect the actual problems in the classroom. This study will be based on the reality of classroom observation to overcome the above shortcomings. Code conversion is an essential part of TCSL teaching. Some scholars have studied these aspects recently, but they only focus on one direction, such as teacher code conversion or student code conversion. This paper extends the research filed to two aspects, namely, both teachers and students use code conversion in the meantime, then investigate and analyze the different reasons and functions of code conversion, which can better enrich the training contents of TCSL teachers and improve the quality of training and professional level. In the long run, the results of the research can help to ensure high quality teaching.

This study is of great importance because it outlines interesting phenomena of language and social transcendence, especially in TCFL classroom settings. As a novel concept, TCFL itself has not been fully studied by scholars or educators so far. And this study pays special attention to code conversion in TCFL, which can be used as an appropriate perspective to explore TCFL.

C. The Questions of the Research 
Although there are many researches on code switching in English environment, there are few researches on TCSL settings. In order to study the current situation of code switching in TCSL, both teachers and students discuss the functions and reasons of code switching, hoping to clarify the research of teacher talk in this field. The purpose of this study was to answer the following questions:

(1) Is there code switching in TCSL classroom? If so, what is their attitude?

(2) What are the reasons why teachers switch passwords in TCSL class?

(3) How does the teacher's undefined code conversion match the students' undefined expectations and the situation in which code conversion should be used?

\section{The Structure of the Research}

This paper is composed of five parts: part one, it's about introduction; part two, it's literature review; the third part is methodology; part four is result analysis and discussion; the last part discusses conclusion and implications to teaching Chinese as a second language.

\section{LITERATURE REVIEW}

This part mainly introduces the definition of code and code switching. In addition, it also discusses the research of code conversion, including foreign research and domestic research. Code switching in TCSL classrooms is also included.

\section{A. Definition of Code and Code Switching}

\section{The Definition of Code}

In some sociolinguistics reference books, code is usually used as a neutral word to represent any sign system of human communication. It can be a language, dialect, linguistic form or registered form according to Crystal, D. and Michael Aceto (2012). It emphasizes that the language system, as an abstract code, is composed of its meaning loaded components. These components have different expressions in different styles, registration methods and even different social groups.

2. The Definition of Code Switching

Different researchers put forward different definitions according to their own understanding about code switching. In the field of linguistics, Uriel (1953) lays a fundamental base for the code-switching research through his book Language in Contact: Findings and Problems. Haugen (1956) defines the term "code-switching." It refers to the phenomenon that bilingual speakers in the discourse use some completely unfamiliar vocabularies of another language." According to the USA linguist Myers-Scotton (1993), the definition of code switching refers to the variants of two or more languages used in the same dialogue or talk. Code switching is a policy for specific communication settings. For example, Trudgill (1986) holds that code-switching occurs when communicators switch their codes for meeting pragmatic needs. Verschueren (2000) points out that code-switching which refers to the alternation of languages or language variations, and it is an extremely popular language strategy especially in oral communications. Hudson (2000) makes a point that sociolinguistics explores the relation of society and language and classify the study of sociolinguistics into the category of linguistic study.

\section{B. Approaches to Code Switching}

Code switching, as the core part of bilinguals discourse, has been studied in detail from different perspectives since 1970s, namely, the sociolinguistics approach, the grammatical approach, the psycholinguistics approach, the discourse - analytic approach and the pragmatic approach.

\section{Researches on Code Switching}

\section{Overseas Research}

In recent years, there are more and more researches on code transformation in language classroom environment. However, the code conversion study in the classroom is different from the code conversion study in other places, because the school is an institutional environment, and the goal of the teacher aims to educate students and students are able to learn the second language/foreign language, such as Chinese.

As a common phenomenon in language contact, code switching, scholars began to paid attention to it in the $1920 \mathrm{~s}$ in foreign countries. However, it did not attract wide attention from scholars at that time. Since 1970s, it has been widely concerned in western academic circles. From the perspective of research, code switching can be classified from the perspectives of grammar, sociolinguistics, psycholinguistics and pragmatics.

From the perspective of grammar, Poplack (1980) proposed that the alternation of two languages is not a random behavior, but it is controlled by free morpheme constraint and equivalence constraint. The study of code switching from the perspective of grammar interprets some features of code switching at the syntactic level. However, its interpretation that is usually based on English and other western language systems, which is not fully applicable to the study of Chinese-English code switching. The study of code switching from the perspective of sociolinguistics focuses on the relationship among social factors such as national identity, background, gender, age, social economic status, and explores the social motivation of code switching. Gumperz (1982) proposed situational code switching and 
metaphorical code switching, among which Myers-Scotton's (1993) markedness model theory is a prominent representative.

From the perspective of psychology, this paper mainly discusses the specific language ability and psychological activities of code switching. This kind of research is often combined with social linguistic perspectives, especially the accommodation theory proposed by Giles \& Clair (1979), which is mainly used to explain the influence of psychological motivation and emotion on verbal communication strategies. From the perspective of pragmatics, researchers (Yu Guodong, 2000; Stell, 2012) believe that code switching originates from people's adaptation to long-term successful communication, and they pay more attention to the dynamic characteristics of language, which is also the research perspective of this paper.

The motivation of code switching has been a hot topic in academic circles. In recent years, foreign researchers have conducted a series of surveys from business contacts, online communication, classroom teaching and other scenarios (Myslin \& Levy, 2015; Aichhorn \& Puck, 2017). It can be seen that foreign scholars have broadened their research fields.

2. Domestic Research

With the enhancement of China's comprehensive vitality, China's influence on the world is growing. More than 60 Confucius Institutes have been established in more than 30 countries and regions around the world. A growing number of people in the world choose to learn Chinese. Since 2002, China has successfully held many "Chinese Bridge" competitions, which has become an important platform for international college students to learn Chinese as well as its splendid culture. All these clearly show the irresistible trend of teaching. Therefore, it is of great significance to study TCSL.

As an important part of TCSL, code switching plays an indispensable role in influencing learners' uncertain Chinese acquisition. Compared with foreign countries, the research on code switching in China started relatively late. Wang Dexing (1987) first introduced the theory of code switching in his article "review of code switching". Most of Chinese scholars focus on bilingualism. With the development of society, the research trend has changed from static to dynamic.

In terms of theory, code switching in China is interpreted from the perspective of sociolinguistics and syntax, which is the same as that of foreign countries. Although code switching began to enter the field of vision in the late 1980s, scholars have carried out research from the perspectives of pragmatics, systemic functional linguistics, syntax, social psycholinguistics, cognitive linguistics and second language acquisition, and they have made great achievements. The research contents include not only the macroscopic summary, but also the pragmatic value, syntactic structure, social function and neural cognition specific research on knowledge (Cheng Wei, 2013; Wang Lin, 2014; Fan Lin, Lu Zhi, 2015; Sun Mingming, Tong Minqiang, 2016). In the field of foreign language education, most of the researches focus on the code switching of teachers in foreign language teaching, such as what kind of language teachers should use and its impact on teaching, while the research on code switching of extra-curricular English learners is relatively less. During the research on English learners, young foreign language learners, especially children in primary education stage, have attracted more attention, and classroom observation research is more than extracurricular investigation research (Qian et al. , 2009; Sampson, 2012; Crutchley, 2015).

In general, most of the researches on code switching in China are based on foreign theories and combined with the specific situation in China. Although there are more case studies on code switching in recent years, the depth of research needs to be further deepened, and new discoveries and theories are still lacking, which need to be further strengthened in the follow-up studies.

\section{Code Switching in the Classroom of TCSL}

With the rapid development of China's economy and the deepening of education reform, more and more foreigners come to China to learn Chinese. At present, there are more than 25 million foreign students learning Chinese in the whole world. In recent years, the number of foreign students who have completed their studies in China has increased dramatically. As a second language teaching, Chinese has become an important part of Chinese middle school and higher education. Besides, it is an important way to spread Chinese culture across the globe. And it refers to the natural language used by Chinese teachers as a second language to achieve communication purposes and complete teaching tasks. Furthermore, classroom language and teaching are included. So we must know that the classroom language is not the mother tongue of foreign students or other language media, but the target language of second language learners.

\section{METHODOLOGY}

\section{A. Objective of the Experiment}

Language is a teacher's professional tool, and language ability is the primary condition for them to complete teaching. Teachers ask for the successful implementation of the teaching plan and the information available to students. The teaching conversion of Chinese as a second language in classroom is a kind of code conversion in special language environment. This paper makes a further analysis of teacher talk through classroom observation and interview, including the language code conversion from Chinese to English used in classroom organization. As a second language, the purpose of English is to put forward reasonable suggestions through the observation and analysis of teacher talk in Chinese teaching and second language teaching, so as to improve teachers' level. 


\section{B. Experimental Methods}

The scope of this paper is from the theoretical form of teacher code conversion, discourse to empirical research, to explore the current situation, characteristics, existing problems and causes of teacher code conversion in teaching classroom. In view of these problems, this paper puts forward some effective suggestions to guide foreign language teaching and improve the teaching quality of Chinese as a second language teaching classroom, and puts forward some suggestions. In the classroom teaching of Chinese as a second language, the code conversion is effectively realized and the teaching function is realized to some degree. The basic ideas of this study can be summarized as follows: theoretical form, case study, proposals and implications.

\section{Class Observation}

This study compares and analyzes the situation and characteristics of the two groups of teachers. Due to the uncertainty of teacher talk and lack of teaching experience, more attention is paid to the characteristics of experienced teachers' discourse. Finally, it summarizes the characteristics of teachers using Chinese as a second language in class.

1. Subject

This study is based on the investigation of Beichen Bilingual School in Shanxi Province. Among some teachers who teach Chinese as a second language, four teachers have been selected, and their classroom language is regarded as the experimental object of learning in Chinese teaching. They are all front-line workers engaged in Chinese as a second language teaching, and regard teachers undefined classroom discourse as the object of study, because they can best represent the linguistic characteristics of Chinese as a second language. The four teachers were divided into two groups: the first group was composed of two teachers, a man and a woman, both aged 30 and under, who taught TCSL for only three months. To facilitate their description in the paper, they were marked as Tel, Te2; Group II and made up of one male and one female teacher, they are between 30 and 40. What's more, they have been engaged in teaching Chinese as a foreign language for many years and have rich teaching experience. In order to carry out the research more accurately, they are marked Ti1 and Ti2 respectively. In this paper, many studies have shown that the characteristics of input language are greatly influenced by the speaker's uncertain experience of the same discourse. Therefore, the teaching content of the experiment in this paper is the same. The premise of the experiment is confirmation. Every test teacher, they use standard language expressions, accurate pronunciation, fluent but moderate speed, and no grammatical errors. All of the above factors can provide standard and specified language input for international students. The information of the four teachers in the study is shown in table 3.1 .

TABLE3.1

DEMOGRAPHIC INFORMATION OF THE EXPERIMENTING TEACHER

\begin{tabular}{lllll}
\hline Group & Teachers & Sex & Age & Teaching Age \\
\hline \multirow{2}{*}{ Group1 } & Te1 & Male & 28 & 3 months \\
\cline { 2 - 5 } & Te2 & Female & 26 & 3 months \\
\hline \multirow{2}{*}{ Group2 } & Ti1 & Male & 35 & 5years \\
\cline { 2 - 5 } & Ti2 & Female & 37 & 8years \\
\hline
\end{tabular}

1. Procedures

(1) Classroom recording. As an observer, the author enters the classroom and selects a corner position to observe the overall situation of the classroom. The recorder is placed on the table in front of the author and can be manipulated by the author. In most cases, the recorder is placed close to the teacher to record the teacher's conversation more clearly and complete the recording successfully. The recording time of each teacher is two cycles, namely 90 minutes.

(2) Converting the recording into written language. This step is to use Chinese as a second language to teach the recording materials in the recording materials.

(3) Statistical analysis. The experimental corpus is adopted and collected through the conversion of the teacher's classroom recording when the test teacher converts the classroom teaching into a second language course into a written text. They have four Chinese teachers. They are marked Te group and Ti group. Their teaching scripts were used as guidance samples for research. The effective data collected by SPSS and Microsoft Excel 2003 software, which show that this method can reduce errors to some extent, but it is time-consuming and not suitable for large-scale corpus collection. However, for small sample studies, the situation is very good

\section{RESUlt ANALYSIS AND DiscUSSION}

Feedback on teacher talk, including evaluation and expectation, is an important part of teacher talk research. We are based on the way that learners observe teachers and hope to achieve expectations.

\section{A. Analysis of Classroom Observation}

The number of code conversions about teacher talk is not the most critical factor affecting the results of classroom interaction. Instead of it, the results of classroom interaction depends on the circumstances. From the classroom observation results of Chinese as a second language teaching, we can draw a conclusion, the teacher-centered classroom teaching mode has been greatly expanded. In the two experimental groups, the input of teacher talk is very large. 
Obviously, teacher talk is dominant. This is mainly based on the current situation of primary school students' uncertain Chinese level, teachers may pay more attention to the teaching of new words and grammar points so as to promote the accumulation of new knowledge and prepare for the next learning state. There is no doubt that this method is extremely effective. Finally, it is the difference between the two groups. Classroom teachers are the quality of teachers' discourse, which is the second language to promote Chinese teaching.

\section{B. Amounts of English Code Switching in Teachers'Discourse}

According to the records, the author calculates the ratio of teacher dialogue, student conversation and teacher code conversion in two periods of the class. The results are shown in Table 4.1.

TABLE 4.1

The Amounts of Teacher's Talk, Students' TALK AND TeacheR's Code Switching In PROPORTION

\begin{tabular}{|c|c|c|c|c|c|c|c|c|}
\hline \multirow{2}{*}{ Group } & \multirow{2}{*}{ Teachers } & \multirow{2}{*}{$\begin{array}{l}\text { Time } \\
\text { (minute) }\end{array}$} & \multicolumn{2}{|c|}{ Teacher's Talk } & \multicolumn{2}{|c|}{ Student's Talk } & \multicolumn{2}{|c|}{ Teacher's Code Switching } \\
\hline & & & Times & Percentage & Times & Percentage & Times & Percentage \\
\hline \multirow{2}{*}{ Group1 } & $\mathrm{Te} 1$ & 90 & 68 & $75.6 \%$ & 10 & $11.1 \%$ & 12 & $13.3 \%$ \\
\hline & $\mathrm{Te} 2$ & 90 & 67 & $74.4 \%$ & 8 & $8.9 \%$ & 15 & $16.7 \%$ \\
\hline Total & Group1 & 180 & 135 & $75.0 \%$ & 18 & $10.0 \%$ & 27 & $15.0 \%$ \\
\hline \multirow{2}{*}{ Group2 } & Ti1 & 90 & 54 & $60.0 \%$ & 13 & $14.4 \%$ & 23 & $25.6 \%$ \\
\hline & $\mathrm{Ti} 2$ & 90 & 53 & $58.9 \%$ & 15 & $16.7 \%$ & 22 & $24.4 \%$ \\
\hline Total & Group2 & 180 & 107 & $59.4 \%$ & 28 & $15.6 \%$ & 45 & $25.0 \%$ \\
\hline
\end{tabular}

It can be seen from the data reflected in table 4.1 that the proportion of inexperienced teachers in Te team and experienced teachers in Ti team is mainly $50 \%-80 \%$ in the whole classroom discourse. There was no significant difference in the number of teachers between the two groups $(\mathrm{t}=0.64, \mathrm{P}<0.01)$. $\mathrm{T}$ and $\mathrm{P}$ mean the data obtained from the comparison. If $\mathrm{t}>0.05$, then if $\mathrm{P}<0.05$, the statistical data we input shows that the experimental data is positive distribution. There are more important cases to reveal the problem of teacher code switching in Chinese teaching as a second language. Teachers' undefined Te2 texts are the least, accounting for $55.6 \%$, and teachers' code switching is the most. This shows that teachers can mobilize students' uncertain enthusiasm and improve teaching quality through Chinese English code conversion in class. In Tel's line 1, the number of students is 11.1\%, while in Til's line 1, the number of students is $14.4 \%$. From both Te and Ti groups, it can be found that the number of students is not high. In class, the average number of students in each group was $13.35 \%$ and $15.55 \%$ respectively, this requires that students need to consciously perform code-switching to improve their abilities. In class Ti2, students scored the highest and it accounts for $16.7 \%$. However, in Te 2 classrooms, the minimum percentage of students is $8.9 \%$, which is lower than the number of teacher code conversions in Te2. This shows that experienced teachers can call the vulnerability code correctly to better mobilize students to actively learn Chinese so as to optimize learning effect. In conclusion, as long as teachers and students use code switching consciously in the classroom, bilingual ability can be improved.

\section{CONCLUSION AND IMPLICATIONS TO TSCL}

This part mainly discusses the conclusions and findings of the paper. In addition, some research findings are also presented. In addition, it also brings some enlightenment to TSCL.

\section{A. Conclusion}

Language is the product of society and complex social phenomena, especially all open systems. However, language connections are more complex. Contact occurs in communication between users in different languages, as well as in the voice of users. With the continuous improvement of China uncertain national strength and international status, the number of Chinese students studying in China is increasing. However, it has become an important task for TCSL teachers to guide international students to learn Chinese as soon as possible and master the basic knowledge of Chinese. With the rise of sociolinguistics and psychology as well as the development of modern teaching technology, TCSL has made many unique and innovative achievements in China. Through classroom observation, qualitative and quantitative analysis of code conversion phenomenon is necessary. The research results are summarized as follows:

First of all, the purpose of Chinese English code conversion should be used in time and correctly. TCSL teachers should meet the teaching needs and achieve the teaching objectives so as to achieve the purpose of classroom communication and interaction.

Secondly, using code switching in class is a good reflection of foreign language knowledge. This will help teachers to establish a better image of teachers among students and enhance students' uncertain confidence in learning Chinese.

Thirdly, for teachers, the effective use of code conversion in the classroom is a useful teaching method, which can improve the active communication between teachers and students.

Finally, in the teaching process, teachers should clearly point out that the ultimate goal of TCSL to train students with certain Chinese knowledge and enable them to communicate successfully in Chinese. So when the teacher speaks Chinese, the principle of integrity and appropriateness should be followed in English code conversion. It is also necessary to take advantage of this trend to let students know that code conversion is the teaching method at the primary stage of TCSL, not the teaching goal. With the students' mastery of Chinese knowledge and the gradual improvement of 
language proficiency, the phenomenon of code conversion used by TCSL classroom teachers will gradually decrease.

\section{B. Findings of the Paper}

The study of code conversion in Chinese as a second language classroom teaching is of great practical value for evaluating the teaching effect of teachers and improving the teaching of Chinese as a foreign language. As a TCSL teaching method, the teaching of Chinese as a second language is an important contribution to foreign language teaching. Therefore, in this part, the author analyzes the causes of these problems according to results. At the same time, learning from the international learning experience of some developed countries, the corresponding improvement measures are put forward to further strengthen the research on teaching theory and teaching policy, and promote the sustainable development of communication and understanding. Only in this way, can we switch between Chinese and English as easily as possible.

\section{Implications to the TSCL}

According to the questions raised by the authors in the first part, the experiments have been analyzed in detail. The answers to these questions can be concluded from two aspects: For one thing, there is a phenomenon here that students still convert Chinese into English in TCSL class, and it plays a very important role in Chinese class. For another, as a new teaching method, learning conversion has been widely accepted by modern language teachers and students. There are many reasons for teachers to convert code in TCSL class. The author will make a detailed analysis from the following theoretical basis for the current actual situation.

In TCSL class, teachers use code conversion according to objective and subjective factors. In order to adapt to classroom communication and achieve the purpose of teaching, teachers sometimes do some functional code conversion. In terms of code conversion, the appearance of function effect has objective and practical significance. It plays an active and positive role in filling the language gap and reducing the communication between teachers and students.

First of all, language is a social phenomenon, it has different functions. The realization of language function is embodied in the choice of language form. Code switching in classroom discourse can not only express some concepts, but also express different interpersonal meanings.

Secondly, metalanguage is a language related to language. It can mark and evaluate the target language and target information. Transcendental functions are used in metalanguage, usually between sentences. Especially in the context of vocabulary usage, grammatical structure and cultural value in the second and first language phase. When teachers translate Chinese into English, they usually express similar expressions between Chinese and English, and then explain their meaning and usage in Chinese and English respectively. Through this comparison, students can easily grasp the learning content.

Thirdly, code switching is a strategy or means that people use in language communication. The user's undefined motivation is hidden behind. The reason why people do not define conscious code conversion is limited by some social factors and some subjective motives of language users. Therefore, for the establishment of teachers and students and the analysis of a variety of consistent classroom code conversion interpretation, researchers should combine the so-called environmental factors of different languages to switch their linguistic codes. Besides, in future research, researchers can learn from the limitations and deficiencies of this study, and make the results more reliable in terms of framework selection, method design and result analysis. Only in this way can students' English ability be developed in an all-round way.

\section{REFERENCES}

[1] Aichhorn, N. \& J. Puck. (2017). "I just don't feel comfortable speaking English": Foreign language anxiety as a catalyst for spoken-language barriers in MNCs. International Business Review, 4, 749-763.

[2] Crystal, D. \& Michael Aceto. (2012). English as a Global Language. TESOL Quarterly, 31, 807-808.

[3] Crutchley, A. C. (2015). Bilingual compound verbs in children's Panjabi-English code switched narratives. Linguistic Approaches to Bilingualism, 1, 2-29.

[4] Cheng Wei. (2013). Analysis on the Phenomenon of Network Communication Code-switching Based on Adaptation Theory. Shandong Foreign Language Teaching, 2, 44-49.

[5] Fan Lin, Lu Zhi. (2015). The Processing Mechanism of Code Switching in the Process of Bilingual Language Production: From Behavioral Research to Neurocognitive Research. Foreign Languages and Their Teaching, 1, 38-44.

[6] Giles, H. \& R. N. S. Clair. (1979). Language and Social Psychology. Baltimore: University Park Press.

[7] Gumperz, J. J. (1982). Discourse Strategies. London: Cambridge University Press.

[8] Haugen, E. I. (1956). Bilingualism in the Americas: A Bibliography and Research Guide. Alabama: Alabam a University Press.

[9] Hudson, R. A. (2000). Sociolinguistics. Beijing: Foreign Language Teaching and Research Press.

[10] Liebscher. (2005). Learner Code-switching in the Content Based Foreign Language Classroom. The Modern Language Journal, 89, 234-247.

[11] Myslin, M. \& R. Levy. (2015). Code-switching and predictability of meaning in discourse. Language, 4, 871-905.

[12] Myers-Scotton, C. (1993). Social Motivations for Codes-witching: Evidence from Africa. Oxford: Clarendon Press.

[13] Poplack, S. (1980). "Sometimes I'll start a sentence in Spanish Y TERMINO EN ESPANOL": Towards a topology of code-switching. Linguistics,7-8, 581-618.

[14] Qian, X. F., G. S. Tian \& Q. A. Wang. (2009). Code switching in the primary EFL classroom in China-Two case studies. System, 
4, 719-730.

[15] Sampson, A. (2012). Learner code-switching versus English only. ELT Journal, 3, 293-303.

[16] Stell, G. (2012). Ethnicity and code switching: Ethnic differences in grammatical and pragmatic patterns of code switching in the free state. Pragmatics, 3, 477-499.

[17] Sun Mingming, Tong Minqiang. (2016). Grammatical Analysis and Social Function of Chinese English Code Switching in TV Advertisements. Foreign Language Research, 4, 105-108.

[18] Trudgill, P. (1986). Dialects in contact. Oxford: Basil Blackwell.

[19] Uriel, W. (1953). Languages in Contact. Findings and Problems (second printing in1963). The Hague: Mouton.

[20] Verschueren, J. (2000). Understanding pragmatics. Beijing: Foreign Language Teaching and Research Press.

[21] Wang Dexing. (1987). A Review of Code-switching Research. Foreign Language Teaching and Research, 80, 31-36.

[22] Wang Lin. (2014). A Probe into the Syntactic Variation of Chinese-English Code-switching-Analysis of Verb Syntactic Valuation Based on Tree Bank. Foreign Languages and Their Teaching, 5, 47-53.

[23] Yu Guodong. (2000). A Pragmatic Study of Code Switching. Journal of Foreign Languages, 6, 22-27.

Juan Ma was born in Linfen, China in 1993. She received her Bachelor's degree in English from Lvliang University, China in 2017. She is currently a postgraduate in Shanxi Normal University, Linfen, China. Her research interests include applied linguistics and second language acquisition. 